\title{
Effect of sludge age on the consortium of microorganisms microbial consortia developed in MFCs
}

\author{
S. Mateo ${ }^{1}$, N. Zamorano-López ${ }^{2}$, L. Borras ${ }^{2}$, F.J. Fernandez ${ }^{1}$, P. Cañizares ${ }^{1}$, A. Seco ${ }^{2}$, M.A. \\ Rodrigo ${ }^{1, *}$ \\ 1 Department of Chemical Engineering. Faculty of Chemical Sciences\&Technologies. \\ University of Castilla La Mancha. Campus Universitario s/n. 13071 Ciudad Real. SPAIN \\ ${ }^{2}$ CALAGUA - Unidad Mixta UV-UPV, Departament d'Enginyeria Química, Universitat de \\ València, Avinguda de la Universitat s/n, 46100 Burjassot, Valencia, Spain
}

\begin{abstract}
BACKGROUND: This work is focused on the assessment of the performance of mini-scale airbreathing microbial fuel cells (MFCs), by monitoring the evolution of the bio-electrogenic activity for a period of 40 days and by comparing the microorganisms populations developed in each of the MFC after this period.

RESULTS: Five MFCs were operated at sludge ages ranging from 1.4 to 10.0 days. Results showed the superb performance of the MFC operating under a sludge age of 2.5 daysDesulfuromonas, Syntrophothermus, Solitalea, Acholeplasma, Propionicimonas, Desulfobacula and Sphaerochaeta are proposed as potential responsible for the bioelectrogenic activity.
\end{abstract}

CONCLUSIONS: Microbial population analysis through Illumina amplicon sequencing demonstrated that despite all MFCs were seeded with the same mixed culture inoculum, the biological cultures developed in the suspension and the biofilm are completely different and depend strongly on sludge age. 


\section{Keywords}

Microbial fuel cell; Sludge age; Electrogenic Bacteria; Biofilm; Illumina

\section{Highlights}

- Sludge age is a key parameter for the selection of electrogenic cultures in MFCs and affects strongly to its efficiency

- Operating under 2.5 days of sludge age results in a superb performance of MFCs.

- Various phylotypes are affected by sludge age in the same fashion than the electricity produced by the MFC

- Desulfuromonas, Syntrophothermus, Solitalea, Acholeplasma, Propionicimonas, Desulfobacula and Sphaerochaeta responsible for the bio-electrogenic activity

- Microorganisms contained in the suspension influences the composition of the biofilm.

* author to whom all correspondence should be addressed: manuel.rodrigo@uclm.es 


\section{Introduction}

Microbial fuel cells (MFCs) have been studied deeply since the discovery of the ability of many microorganisms to donate electrons to an electrode, which opened the possibility of using these microorganisms to harvest the energy contained in the organic matter of wastewater. A lot of efforts have been made from that moment, most of them related to study the influence on the performance of the MFCs of the electrodic materials (1,2), cell design (3), carbon source and concentration of the fuel fed $(4,5)$, catalysts $(6-10)$, origin of the sludge seeded (11), external resistance (12), environmental and operational conditions (13), decrease of the internal resistance (14) and tolerance to real wastewaters. However, after some decades, the production of electricity yielded by individual MFC is rather low and the key points to increase the productivity seem to be the miniaturization of the MFC and the later stacking of individual mini-cells and the development of very efficient electrogenic communities (15-19).

Microorganisms play a major role in the generation of electricity either transferring electrons from their metabolic reactions to the anode or mediating the electron transfer (20). They can be found as a biofilm on the anode surface, forming superimposed layers on it or inside the porous of the material, and/or suspended. The transfer of electrons can occur via physical contact bacteria-anode, via nanowires through the extracellular electron transfer at a considerable distance from the electrode and via diffusional redox species that facilitates the electron transfer. Direct transfer only takes place with microorganisms immediately attached to the surface $(21,22)$ while nanowires allow the formation of thicker electroactive biofilms $(23)$. The last way mentioned has a leading role when growing suspended electrogenic communities. In this case, the electron transfer take places through redox mediators produced by the microorganisms or added artificially (24). It is believed that endogenous mediators are more convenient in MFCs, especially in batch cultures (25). 
There is a rather large number of environments that exhibits "electrochemical activity" and in which MFCs have been tested, including sediments in lakes (26), rivers (27) or seas (27), garden compost leachate (28), iron rich soils (29), living rice plants (30), salt marsh (31) and acid hydrometallurgical environments (32). The variety of these environments gives an idea of the potential application of the MFCs and of the diversity of electrogenic bacteria, known and, perhaps, still unknown. Geobacter and Shewanella are known as the electrogenic bacteria par excellence (33), because they are frequently the primary bacteria genera contained in biofilm. For this reason, studies carried out with pure cultures tend to select them in order to enrich the anodic chambers. Geobacter can release electrons directly $(34,35)$ while Shewanella-is believed to synthetize nanowires and to develop mediated electron shuttles (36). However, other species belonging to the phylum of Proteobacteria, Bacteroidetes, Chloroflexi and Cyanobacteria have been found in biofilms of MFCs $(37,38)$. In mill effluent, Desulfuromonas acts as the predominant electrogenic microorganisms (39). It can be grown anaerobically in marine environments $(4,40)$ and also in anoxic deep subsurface brines (41). It is also very common the presence of Arcobacter, Bacillus, Pseudomonas, Cronobacter, Desulfobacter (42) in dark fermentative effluents. Clostridium (43, 44) and Lactococcus (45) are present in fermentative processes and have the ability for electron transfer (46) (47). This ability is also shown by Aeromonas (48) despite of not being dominant. Another genera as Propionicimonas and Azospira are known to play an important role in the exocellular electron transfer (49). The presence of these microorganisms in the biological culture of a MFC is determined by the equilibrium between their growth rate and the rate at which they are purged from the system. Therefore, to select microorganisms, the main manipulate input is the purge of biomass. In suspended cultures of microorganisms, there is a direct effect of the purge and this is typically quantified by the sludge age parameter, which becomes the key parameter for the operation of suspended-solids biological wastewater treatment processes (50-52). For example, Shewanella 
Oneidensis has a growth rate of 0.085-0.04 $\mathrm{h}^{-1}$ (53) while Geobacter Sulfurreducens develops at $0.037 \mathrm{~h}^{-1}$ (54) so under the same conditions, S. Oneidensis requires less time of adaptation than G. Sulfurreducens. At the same way, microorganisms that consume organic matter without generating electricity can be washed from the system. In conclusion, this parameter can be the most relevant to select efficient electrogenic communities (2).

In biofilm cultures, the purge affects only indirectly to the selection of the consortia because it is limited to those detached from the biofilm. The detachment does not depend on the purge of the liquid, but it depends on the thickness and on the shear stress underwent by the biofilm. It is also important to take into account that the enrichment process in MFCs is frequently carried out recirculating the sludge to induce the suspended bacteria to adhere and to form the biofilm on the surface of the anode. It means that the biofilm growth, and mostly to the layers further away from the electrode, surface can be indirectly controlled by regulating the growth of the suspended bacteria. In previous works of our group, it was found that to start up a MFC it is a good practice to operate at large sludge age (10 days) (55) although once the bioelectrogenic activity of the MFC is ongoing, it is much better to reduce the sludge age and to operate at lower values, because at those conditions bioelectrogenic microorganisms prevail(56). Thus, using carbon paper anode in an air-breathing MFC fed with acetate, 2.5 days was found to yield the best results. In double compartment MFC(57), low values of the sludge age were also found to be the optimum, although in this case the MFCs were fed with real winery wastewater. This means that bioelectrogenic microorganisms can compete with non-electrogenic microorganisms successfully under high purging rates but the initial stage in which the biofilm is formed is especially sensitive and needs for larger sludge ages. Hence, sludge age is a key parameter and it should be related to the microbial population and further information is needed about this point. In our previous works, it was also found that the anode material plays a very important role and for the same operation conditions it can help to improve very importantly 
the efficiency of the system. Thus, carbon felt was found to be the most suitable anode material for this application and this was explained in terms of its higher surface area(58).

Taking into account this background, the main aim of this work is to elucidate the role of the sludge age in the production of electricity by operating similar air-breathing MFCs equipped with carbon felt anodes under different sludge ages and to study in depth the presence of the bacterial communities in each case, through a next-generation sequencing Illumina analysis, trying to relate the evidences about performance (shown in the first subsection of the R\&D section) with the biological culture developed in each system (discussed in the second subsection).

\section{Materials and methods}

\subsection{Experimental set-up and operation}

The experimental set-up consists of an auxiliary anodic tank closed to the atmosphere of $50 \mathrm{~mL}$ which contains sludge and the synthetic wastewater that is recirculated continuously by a multichannel peristaltic pump (Heindolph 5201) to the MFC at a flow rate of $3 \mathrm{~mL} \mathrm{~min}^{-1}$ (Figure $1)$.

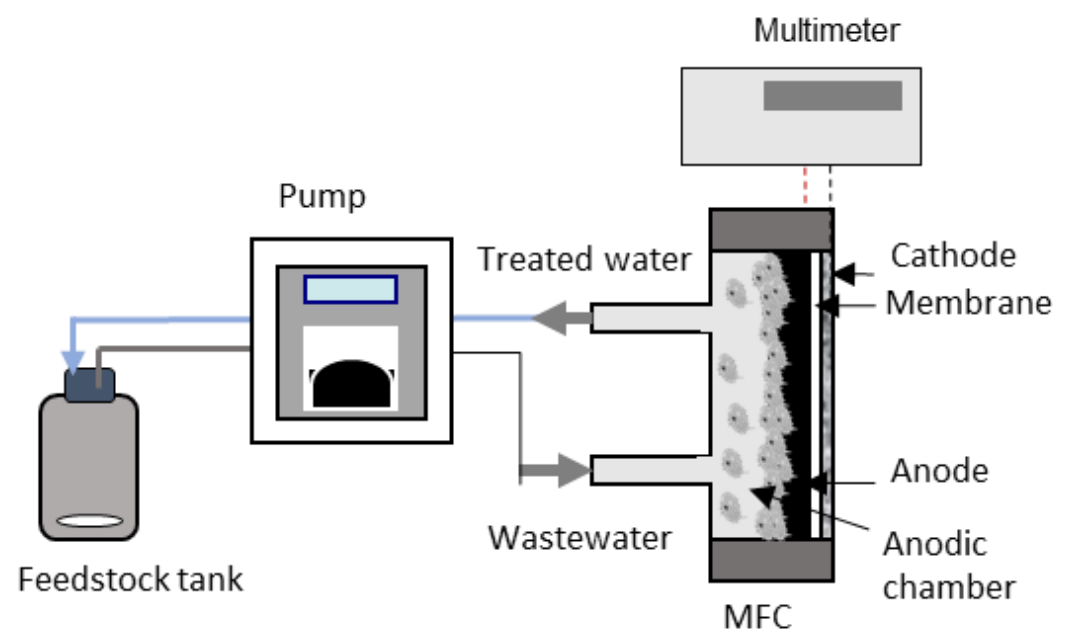

Figure 1. Scheme of the experimental set-up, which was replicated 5 times for each sludge age. 
The system operates in semi continuous mode being fed once a day. Thus, every day an estimated volume is removed from the tank, which is then filled in immediately with the same volume of fresh synthetic wastewater in order to maintain the sludge age that is being evaluated. It is important to note that in this system not only the sludge age changes but also the organic load, which increases with the decrease in the sludge age, as the volume purged (Table 1) is higher and the feeding solution used was the same in all the cases. It is important to take into account that the dilution rate is the reciprocal of the Hydraulic Retention Time (HRT) for the steady state and under absence of a sedimentation stage, the HRT match the sludge age. The selected sludge ages that are object of this study are: 1.4, 2.5, 5.0, 7.4 and 10 days. Likewise, although the concepts of Solid Retention Time and Sludge Age are used indistinctly, it is important to take into account the detail that the second may fits better to the performance of biological processes, taking into account that in living systems, the rate at which microorganisms are purged from the system can be a very important selecting factor between populations and thus, if it is higher than the growth rate of a population, its wash up can be attained. For this reason, regardless the concepts are synonyms and the values are exactly the same, in this work the sludge age terminology is going to be used because we want to stress that the focus is on the population of microorganisms. Table 1 shows the volume that is necessary to be replaced on a daily basis in the auxiliary tank to get the different sludge ages following the equation of $\mathrm{V}$ reactor $(\mathrm{mL}) / \mathrm{V}$ purged $\left(\mathrm{mL} \mathrm{d}^{-1}\right)=$ Sludge age $(\mathrm{d})$.

Table 1. Maintenance Conditions of Sludge age.

\begin{tabular}{|c|c|}
\hline Sludge age (d) & V (mL) \\
\hline 1.4 & 41 \\
\hline 2.5 & 23 \\
\hline 5 & 11.5 \\
\hline 7.4 & 7.75 \\
\hline
\end{tabular}




\begin{tabular}{|l|l|}
\hline 10 & 5.75 \\
\hline
\end{tabular}

Due to the need to have a good comparison between behaviours, five different membrane aircathode MFCs corresponding to the five sludge ages were operated simultaneously in the same place. In this way, the influence of environmental conditions such as temperature, humidity, pressure among others is discarded. Every MFC was built up as similar as possible. The anodic chamber has a volume of $0.346 \mathrm{~cm}^{3}$, available for the circulation of wastewater and suspended microorganisms, and an anodic electrode of carbon felt of $0.865 \mathrm{~cm}^{2}$ of surface area and a thickness of $0.4 \mathrm{~cm}$. The carbon felt used in this work has a specific area of $35.3 \mathrm{~m}^{2} \mathrm{~g}^{-1}$ and an areal weight of $500 \mathrm{gm}^{-2}$, a porosity of $95 \%$ and a roughness of $30 \mu \mathrm{m}$. This electrode is in direct contact with the liquid on one side and with the proton exchange membrane (DuPont ${ }^{\mathrm{TM}}$ Nafion PFSA Membrane) on the other side. Anodic electrode-membrane-cathodic electrode are arranged as close as possible to diminish the internal resistance and anode and cathode are connected externally by a $120 \Omega$ resistance. The cathodic electrode of $0.865 \mathrm{~cm}^{2}$ is exposed to the atmosphere and it is made of carbon paper (Freudenberg C2). This electrode contains a 10\% of Teflon and its catalytic properties were improved by depositing a layer of $0.5 \mathrm{mg} \mathrm{Pt} \mathrm{cm}{ }^{-2}$. The ink was air sprayed keeping the electrode on a 130 degree heating plate to evaporate the dimethylacetamide used as solvent. Finally, the electrode was subjected to a calcination process and $10 \% \mathrm{v} / \mathrm{v}$ phosphoric acid was added to favour the conductivity (59).

\subsection{Inoculation procedure}

MFCs were enriched with the same sludge from an ongoing MFC. In order to guarantee a good distribution of the microorganisms throughout all the system, the auxiliary tank was completely filled with sludge and it was recirculated to the anodic chamber for a day. The second day, 50 $\%$ of the sludge in the tank was removed and fresh sludge was added and recirculated the whole 
day. The third day the same procedure than the second day was carried out. The fourth day, the volume according to Table 1 was removed in each case and replaced by fresh synthetic wastewater. It is important to highlight at this point that every MFC was maintained under conditions of agitation to favour the homogeneity and mass transport.

\subsection{Synthetic wastewater}

Synthetic wastewater as feedstock was used in this study to ensure no changes in the nature of the microorganisms. It has the following composition: $16.10 \mathrm{~g} \mathrm{~L}^{-1}$ of sodium acetate, $2.77 \mathrm{~g} \mathrm{~L}^{-}$ ${ }^{1}$ of sodium carbonate, $1.11 \mathrm{~g} \mathrm{~L}^{-1}$ of potassium dihydrogen phosphate, $1.25 \mathrm{~g} \mathrm{~L}^{-1}$ of calcium chloride, $0.92 \mathrm{~g} \mathrm{~L}^{-1}$ of hexahydrate magnesium chloride, $1.85 \mathrm{~g} \mathrm{~L}^{-1}$ of ammonium sulphate and $0.07 \mathrm{~g} \mathrm{~L}^{-1}$ of ferric ammonium sulphate. After its preparation, and to avoid its degradation, it was sterilized in an autoclave at high pressure and temperature. All the reagents were of analytical grade and purchased from Sigma Aldrich and Panreac.

\subsection{Electrochemical and analytical characterization.}

A multimeter Keithley 2000 registered continuously each 5 minutes the exerted voltage (resistance of $120 \Omega$ ) of every working MFC. A potentiostat/galvanostat AUTOLAB PGSTAT30 was used to carry out frequently polarization curves. After leaving the MFC in open circuit for two hours, the polarization curves were carried out from the Open Circuit Voltage $(\mathrm{OCV})$ to $0.001 \mathrm{~V}$ at a scan rate of $0.001 \mathrm{~V} \mathrm{~s}^{-1}$ and at a step potential $0.01 \mathrm{~V}$. Power curves were obtained according to Joule's Law ( $\mathrm{P}=\mathrm{I} \cdot \mathrm{V})$. Coulombic efficiency was calculated by integrating over time the Coulombs transferred to the anode divided by the stoichiometric theoretical value as suggested Logan in the Equation 1 (60).

$$
\mathrm{CE}=\frac{\mathrm{M} \cdot \int_{0}^{\mathrm{t}} \mathrm{I} \cdot \mathrm{dt}}{\mathrm{n} \cdot \mathrm{F} \cdot \mathrm{V}_{\text {anodic }} \cdot \mathrm{r}_{\mathrm{COD}}}
$$


Previous to the determination of organic matter consumption, samples taken as purge were filtered with $0.45 \mu \mathrm{m}$ of a microfiber filters and then COD was measured following the instructions of the Standard Methods (61). The $\mathrm{pH}$ was measured with a GLP22 Crison $\mathrm{pH}-$ meter. Suspended solids were measured gravimetrically, by the difference of weighing of a 0.45 $\mu \mathrm{m}$ microfiber filter before and after filtering $10 \mathrm{~mL}$ sample at vacuum and kept in an oven at $105^{\circ} \mathrm{C}$ for $24 \mathrm{~h}$.

\subsection{Collection of samples.}

Samples were collected from biofilm and suspended fractions of each MFC after 40 days of operation. For suspended samples, a total volume of $5 \mathrm{~mL}$ was centrifuged at $5630 \mathrm{~g}$ during 10 minutes and for biofilm samples, the same procedure was followed but the surface of the electrode was previously scraped. The supernatant obtained in both cases was removed from samples and the resulting pellet was finally stored at $-20^{\circ} \mathrm{C}$ until DNA extraction procedures.

\subsection{Genomic DNA extraction and Illumina sequencing.}

Extraction of genomic DNA (gDNA) material was performed according to manufacter's protocol within E.Z.N.A Soil DNA Kit (Omega-Biotek). For this purpose, $1 \mathrm{~mL}$ of each stored sample was used. Concentration and purity of the resulting gDNA samples were determined by measured absorbance at 230, 260 and $280 \mathrm{~nm}$ wavelength in a Nanodrop 2000 spectrophotometer (Thermo Scientific). According to the A260/230 and A260/280 calculated ratios (data not shown), all gDNA samples were not contaminated by RNA or humic acids after extraction procedures. DNA content was measured in a Qubit 3.0 fluorometer (Life Technologies) in each sample before libraries preparation.

Preparation of 16S rRNA gene libraries was performed from $0.2 \mathrm{ng} / \mu \mathrm{L}$ of individual gDNA samples. Indexed primers targeting the v4 hyper-variable region of the $16 \mathrm{~S}$ rRNA gene were 
selected for Illumina amplicon sequencing application. Amplification conditions for 515F ( $5^{\prime}-$ GTGCCAGCMGCCGCGGTAA-3') and 806R (5'-GGACTACHVGGGTWTCTAAT-3') primer pair used were: 30 seconds of denaturing stage at $95^{\circ} \mathrm{C}, 28$ cycles of annealing stage, where steps at 95,55 and $72{ }^{\circ} \mathrm{C}$ were successively performed during 30 seconds; and final elongation stage at $72{ }^{\circ} \mathrm{C}$ during 5 minutes. Resulting libraries of $16 \mathrm{~S}$ amplicons were multiplexed in a Nextera XT Index Kit (provided by Illumina) and sequenced on a MiSeq Sequencer 2x300 bp paired-end run, in genomic department of the Fundación para el Fomento de la Investigación Sanitaria y Biomédica de la Comunidad Valenciana (FISABIO).

\subsection{Sequencing data analysis and taxonomic assignment.}

Raw data retrieved from Illumina sequencing was sequentially processed through the following pipeline: first, the prinseq-pl algorithm (62) was applied at the trimming stage, within a qualitythreshold of 30 and a window length of $12 \mathrm{bp}$. The trimmed paired-end reads were joined with default parameters of fastq-join (63), and chimeras were excluded after the application of the UCHIME algorithm (64). Taxonomic assignment was carried out up to genus level, applying a confidence threshold of 0.8, in the Ribosomal Database Project's Classifier tool release 2.11 (65). Relative abundances and population analysis were obtained by means of R software.

\section{Results and discussion}

\subsection{Performance of the MFCs}

Figure 2 informs about the performance under close circuit conditions of one of the microbial fuel cells studied in this work, during the complete duration of the life test carried out. This behavior is representative of the performance of the other four cells evaluated in this study, in terms of the evolution of the parameters under close circuit conditions, although, as it will be 
discussed later on, the steady state reached for each of them is significantly different and this will become the main point of discussion of this paper.

Regarding results shown in the Figure, two different behaviors can be detected in terms of the stages in which the changes can be divided: one for the current density, with three clearly differentiated stages, and other for the TSS and COD consumption, with only two stages.

A)

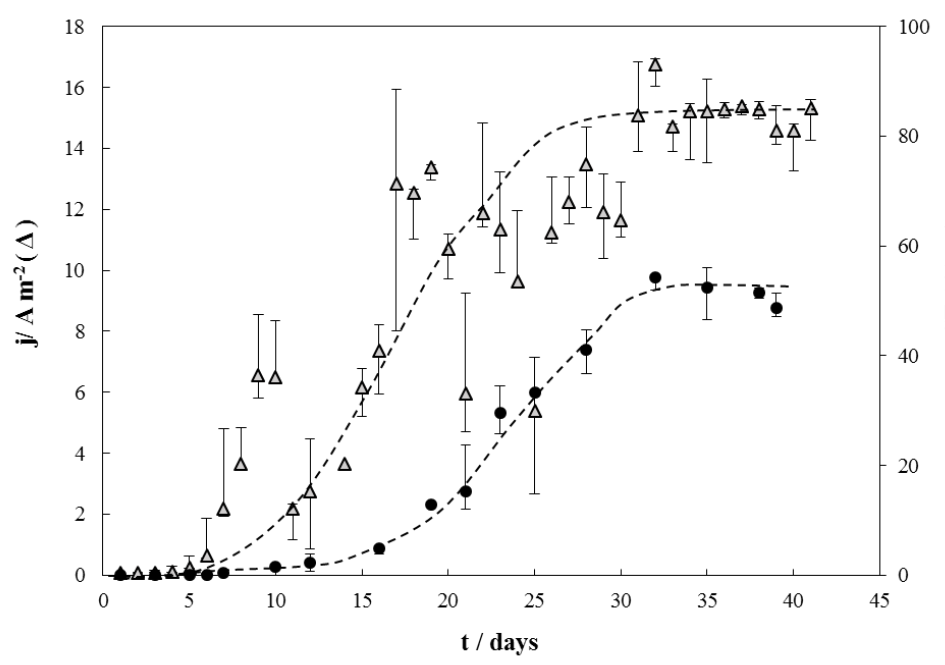

B)

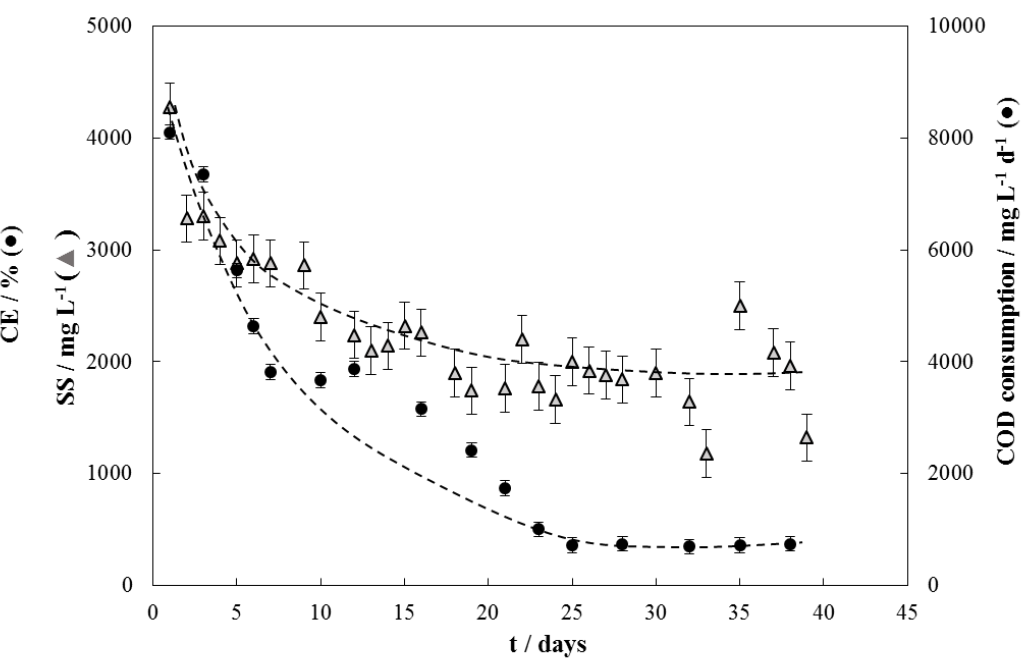

Figure 2. Evolution of the life test of the MFC operated at a sludge age of 2.5 days. A) $(\triangle)$ Exerted current density daily as an average of the current measured hourly in a day with error bars related to the minimal and maximum values obtained each day; (•) Daily Coulombic efficiency with error bars based on the error of the parameters involved. B) (•) COD removed daily and $(\triangle)$ suspended solids in the purge from the anodic tank with analytical error bars. Average temperature: $23^{\circ} \mathrm{C}$.

About the current density under close circuit conditions, which is directly related with the population of bioelectrogenic microorganisms, it can be seen that after a first lag (acclimation) period of less than 6 days, in which the production of electricity is almost negligible, the 
bioelectrogenic culture starts its exponential growth stage, which is completed in about-30 days. Then, the MFC reaches a steady state in the production of electricity, reflected in a stationary current density of more than $14 \mathrm{~A} \mathrm{~m}^{-2}$, which corresponds with an outstanding coulombic efficient of nearly $50 \%$. This value (60) is the relationship between the current produced and the maximum current which can be produced with the total COD consumed so it is an indicative of the fraction of bioelectrogenic microorganisms that are present in the biological culture. As an important fraction of the COD consumed is used not for the production of energy but for the production of biomass, this high value can be indicative of the generation of a biological population strongly bioelectrogenic and, in addition, with a very low biomass yield. At this point, it is important to point out that in the changes of the COD and total suspended solid, only two differentiated stages can be observed discerned (no acclimation as in the production of bioelectricity). In the first stage, there is an important decay in the total population of microorganisms, which means that only a small fraction of the initial population of microorganisms seeded are able to survive under the conditions applied. In addition, the COD consumption decreases very importantly, in more than 8 times during this period. During the first days, the COD removal rate was about $8000 \mathrm{mg} \mathrm{L}^{-1} \mathrm{~d}^{-1}$ while at the steady state only approximately microorganisms oxidises $800 \mathrm{mg} \mathrm{L}^{-1} \mathrm{~d}^{-1}$. It is also interesting to mention that under steady state, the system operated under a constant $\mathrm{pH}$ of 7.52 and a constant conductivity of $15.15 \mathrm{mS} \mathrm{cm}^{-1}$. These values reflects the favourable conditions for the electrogenic bacteria development and transfer processes."

The outstanding development of the bioelectrogenic culture can also be seen in Figure 3, where it is shown the changes in the polarization curves obtained at four different days during the life test carried out. In the onset, a zoom of the polarization curves obtained in the start-up of the MFC demonstrates a low bioelectrogenic content in the biological culture seeded in the MFC. Anyhow, there is a clear shape in both the $\mathrm{V}$ vs $\mathrm{j}$ and the $\mathrm{W}$ vs $\mathrm{j}$ plots, which suggests that the 
sludge seeded contained, at least, a very small presence of bioelectrogenic microorganisms, which will act as seed of the greater bioelectrogenic behavior. In comparing the $\mathrm{V}$ vs $\mathrm{j}$ plots, it can be clearly seen how the OCV increases during the operation of the MFC and stabilizes after one month of operation.

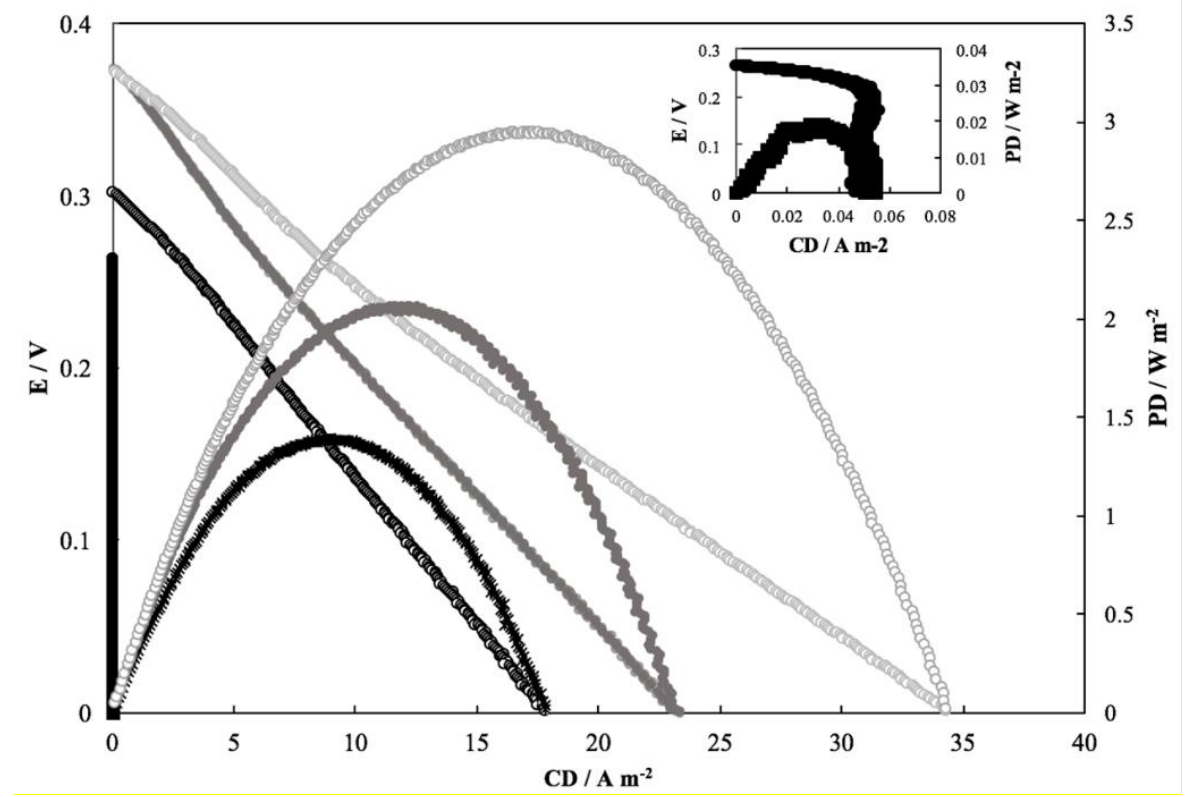

Figure 3. Evolution of the polarization and power curves since the start-up until reaching the steady state: $(\bullet)$ First day with a zoom in the upper right corner; $(\mathrm{O})$ Day 14; $(\diamond)$ Day 28; $(0)$ Day 40.

Another important point is that the slope of the curves decreases with the operation time, indicating the decrease of energy losses and limitations due to the formation of an effectiveness exoelectrogenic biofilm. An active efficient biofilm ensures the good performance of the electrons donation process from the microorganisms to the anode. It is also observed the decrease in the internal resistance from $30 \mathrm{k} \Omega$ at the start-up up to $116 \Omega$ when the system is stabilized. This fact indicates that during the initial period the energy losses were due to the inexistence of mechanisms to transfer electrons and due to the presence of the membrane while during the steady state the internal resistance is mainly governed by the membrane and other negligible factors. As a consequence, the maximum current density attainable increases during time reaching a value as high as $35 \mathrm{~A} \mathrm{~m}^{-2}$, which is a very remarkable value for this type of 
MFCs taking into account the absence of catalyst on the anode that accelerate the electron transfer. This is clearly seen when it is compared with the $0.8 \mathrm{~A} \mathrm{~m}^{-2}$ obtained in a MFC with a carbon felt anode of $25 \mathrm{~cm}^{2}$, a carbonaceous cathode with $0.5 \mathrm{mg} \mathrm{Pt} \mathrm{cm}{ }^{-2}$ and enriched with mixed culture (10); the $20 \mathrm{~A} \mathrm{~m}^{-2}$ reached in a double chamber MFC using anode and cathode of carbon felt under the same operational conditions than our study (66), and the $4.65 \mathrm{~A} \mathrm{~m}^{-2}$ and $0.75 \mathrm{~A} \mathrm{~m}^{-2}$ attained in another double chamber devices of $0.0113 \mathrm{~cm}^{2}$ of carbon felt anode (67) (68). Other studies in literature with a different material in the anode reflected lower achievable current densities. Thus, an air-breathing MFC with $0.16 \mathrm{~cm}^{2}$ of carbon cloth anode reached $0.0073 \mathrm{~A} \mathrm{~m}^{-2}(14)$, another attained $9 \mathrm{~A} \mathrm{~m}^{-2}$ with a characteristically and operationally similar MFC like the previous one but increasing the surface area up $7 \mathrm{~cm}^{2}(69)$. This value decreases down to $2.2 \mathrm{~A} \mathrm{~m}^{-2}$ when carbon paper is used as electrodes (24).

Once, clarified how is the performance of a single cell, it is interesting to compare the steady state reached by the five MFC studied in this work. However, before focusing on this response, it is interesting to compare the transients, and particularly, the time needed to complete each of the stages described before. Regarding this dynamic response, it is important to point out that the acclimation or lag period were $7.0,6.0,9.0,6.0$, and 7.0 days, in the cells operated with SRT of $1.4,2.5,5.0,7.4$ and 10.0 days, respectively. This means that there are no significant differences in the time required for the electrogenic bacteria contained in the sludge seeded to start their development and predominance in the system. The same comment has to be made regarding the exponential growth stage, which lasted after 26.0, 25.0, 32.0, 36.0, 30.0 days in the cells operated with SRT of 1.4, 2.5, 5.0, 7.4 and 10.0 days, respectively. Coming back to the comparison of the steady state results, Figure 4 compares for the five MFC tested the main performance parameters. Regarding current density, results obtained here again allows to conclude that 2.5 days is an optimum value for this type of cells, regardless the anodic material, as it was pointed out in a previous work of this group in which we studied the effect 
of this parameter in MFC equipped with carbon-paper anodes (2). In that paper, it was suggested that shorter SRT washed out some of the bio-electrogenic microorganisms and longer SRT were not adequate because other microorganisms with a lower growing rate can predominate in the biological culture because of their more efficient metabolisms under the particular conditions that they undergo in the anodic chamber. This trend in the current density can also explain the changes observed in the current efficiency, which, anyhow are significantly high for the five sludge age tested.
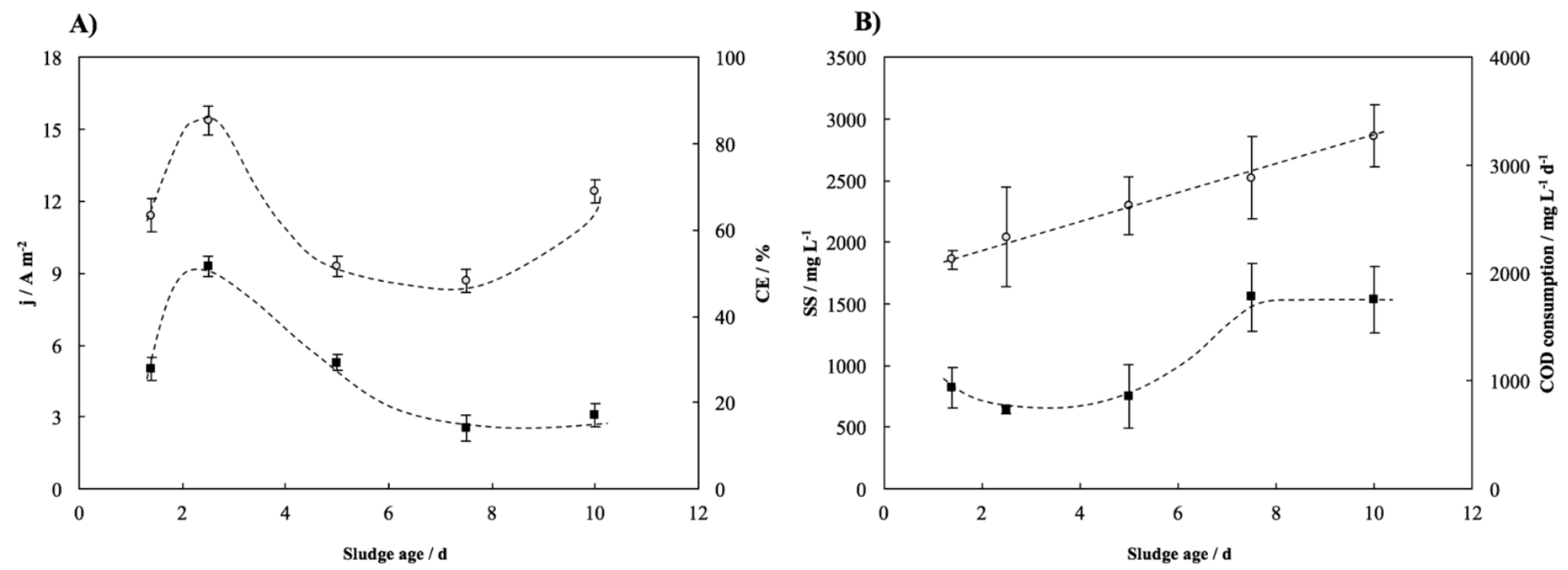

Figure 4. Main performance parameters at the steady state for all the sludge ages tested. A) (O) Current density and (•) coulombic efficiency from an average of five days. B) (O) Suspended solids and (•) COD consumed in a day from an average of five days. Average temperature: $23^{\circ}$ C.

However, the more important effect of the purge of microorganisms is expected to be in the concentration of microorganisms in the suspension and it can be observed in part B of the Figure. The lower the sludge age, the higher the purge of microorganisms and, hence, the lower the steady state concentration of total suspended solids (despite the higher organic load fed to the system). Obviously, this does not affect directly to the microorganisms contained in the biofilm but it informs about serious changes in the bulk of the electrolyte, which can help to 
explain the great differences observed in the production of electricity. Another important observation is the consumption of COD, which obviously increases with the population and it is larger for higher sludge ages. Anyhow, the fashion in which current and COD consumption changes with the sludge age is completely different and informs about the competence of bioelectrogenic and non-bioelectrogenic microorganisms.

During the complete experimental time in which the five MFC were operated, polarization curves were obtained periodically in each of them after leaving the devices two hours in open circuit conditions. Figure 5 shows the main parameters got from this curves. In part A, it can be seen how, despite the performance seems to be stabilized as the dynamic response of the daily voltage under close circuit conditions indicates, the capacity for the production of power could still be improved after 40 days of operation and how the best MFC (that operated at SRT of 2.5 days) reached $3 \mathrm{~W} \mathrm{~m}^{-2}$, which is an outstanding value for the technology used, comparable with the output powers of other similar devices in literature: $1 \mathrm{~W} \mathrm{~m}^{-2}(66), 2 \mathrm{~W} \mathrm{~m}^{-}$ ${ }^{2}(69-71), 0.1 \mathrm{~W} \mathrm{~m}^{-2}(10)(68)(72), 0.6 \mathrm{~W} \mathrm{~m}^{-2}(14,24), 0.07$ (59). As it can be seen in literature, no more than $3 \mathrm{~W} \mathrm{~m}^{-2}$ has been achieved for most of the MFC of the characteristics of that used here. Only two studies has been found with higher values of power density than this work: 6.86 $\mathrm{W} \mathrm{m}{ }^{-2}$ with a relation anode/cathode surface area $1 / 14(73)$ and $4.31 \mathrm{~W} \mathrm{~m}^{-2}$ reached by a glucose fed MFC using $50 \mathrm{~cm}^{2}$ graphite rod as anode.

Regarding the values obtained at the end of the tests in each of the cells, they reflect small differences between the maximum capacities (those shown by the polarization curves) and operation capacities (values shown in Figure 4), in which it seems that performance at the lowest sludge age can be limited at the operation conditions, as the maximum current attainable in that conditions is almost the same than that obtained a 2.5 days of SRT. 

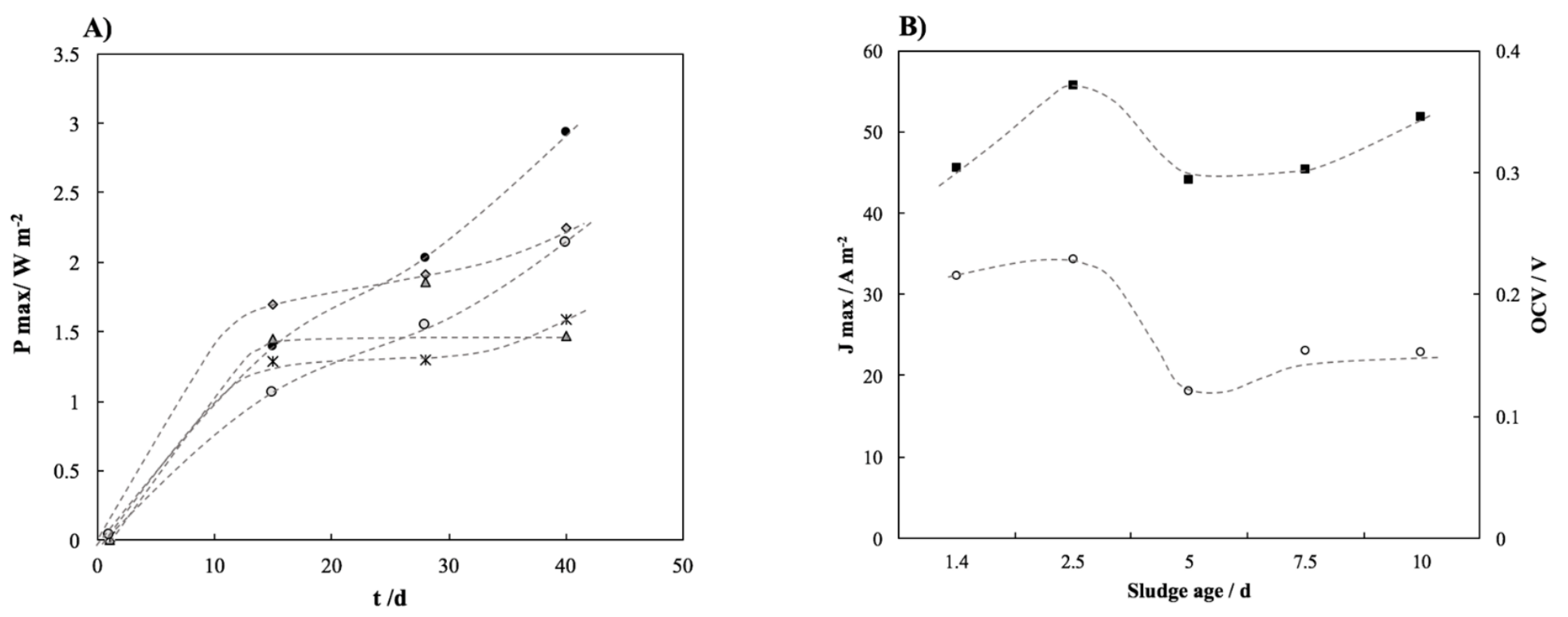

Figure 5. A) Time course of the maximum power density achievable by MFCs tested under the different sludge ages $(\diamond) 1.4$ days; $(\bullet) 2.5$ days; $(\triangle) 5$ days; $(\times) 7.4$ days; $(\bigcirc) 10$ days. B) Evolution of the maximum current density $(\mathrm{O})$ and OCV (•) with the sludge age at the steady state.

\subsection{Characterization of microorganisms}

In order to know more details about these MFCs, the genus of the microorganisms contained in the biofilms and in the suspended culture were studied and compared in terms of percentage of relative abundance of the Archaea and Bacteria population observed in both places, electrode and mixed liquor, of the MFCs. These results are shown in Figure 6. 

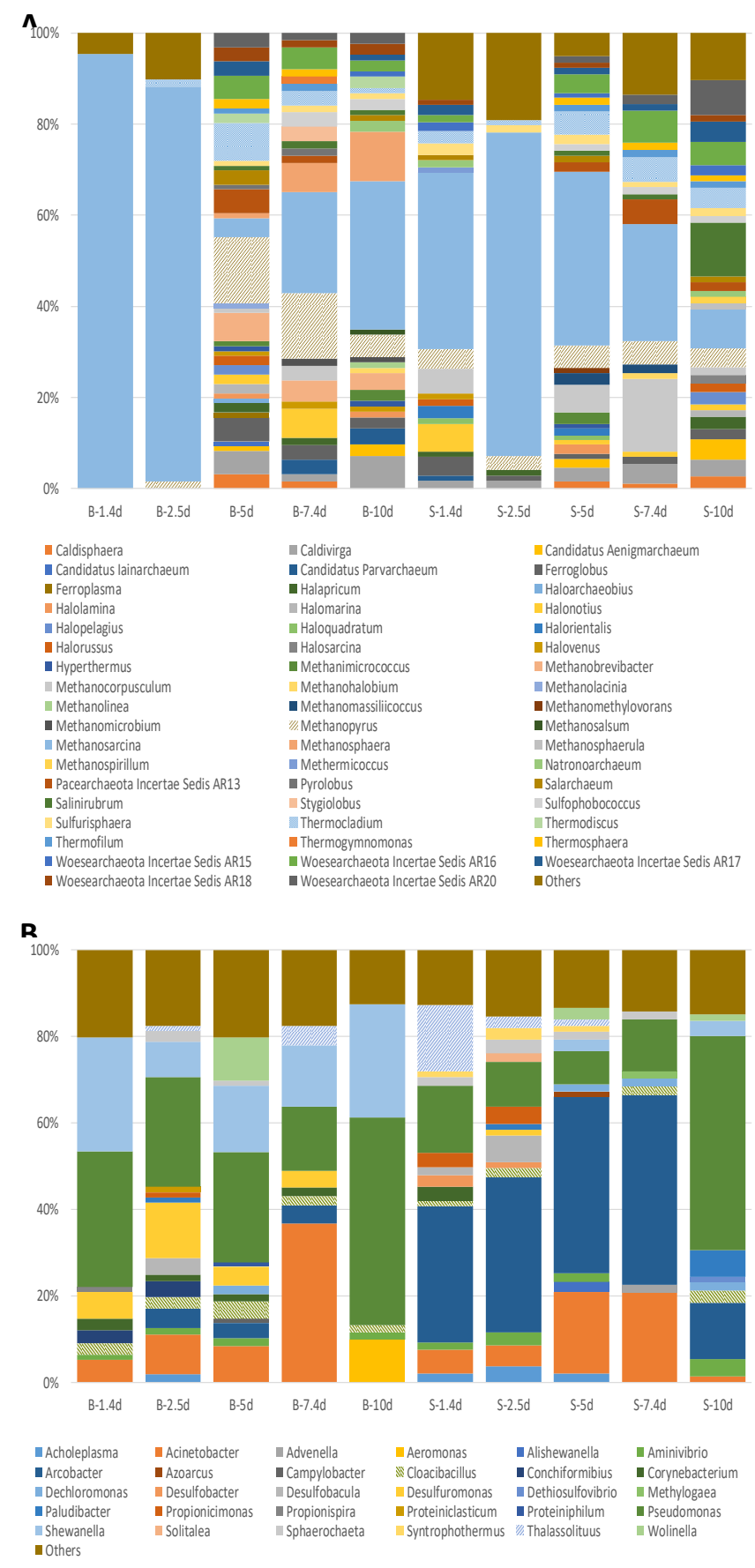

Figure 6. A) Relative abundance of detected Archaea genera: (B) Archaea in Biofilm; (S) Archaea in Suspension. B) Relative abundance of detected Bacteria genera: (B) Bacteria in Biofilm; (S) Bacteria in Suspension.

Not pure cultures but very high diversity cultures are involved in the processes happening in each of the cell. It is worth, pointing out that the sludge age is a very good parameter to select 
populations of microorganisms in MFC, as it is well-known to be in suspended solid biological wastewater treatment processes. Another important point is that in most cases, percentage of each genus changes progressively with the sludge age, clearly pointing out that this parameter can be used to control the type of microorganisms contained in the anodic chamber and biofilm of the MFC. From the plots, in percentage the mostimpertant dominant bacteria genera seem to be Pseudomonas, Acinetobacter, Shewanella and Arcobacter and the most important genera of Archaea domain are Methanosarcina, Methanopyrus, Thermocladium and Methanocorpusculum. It is important to point out that the ratio between archaea and bacteria is not maintained constant but depends on the SRT. This is shown in Figure 7, where it can be clearly pointed out that Archaea population is, at least, one log-unit below bacteria population. In addition, It can be seen that role of Archaea becomes more important at low sludge age, both in the biofilm and in the suspension, although ratios are slightly different and they are higher relative abundance in the biofilm.

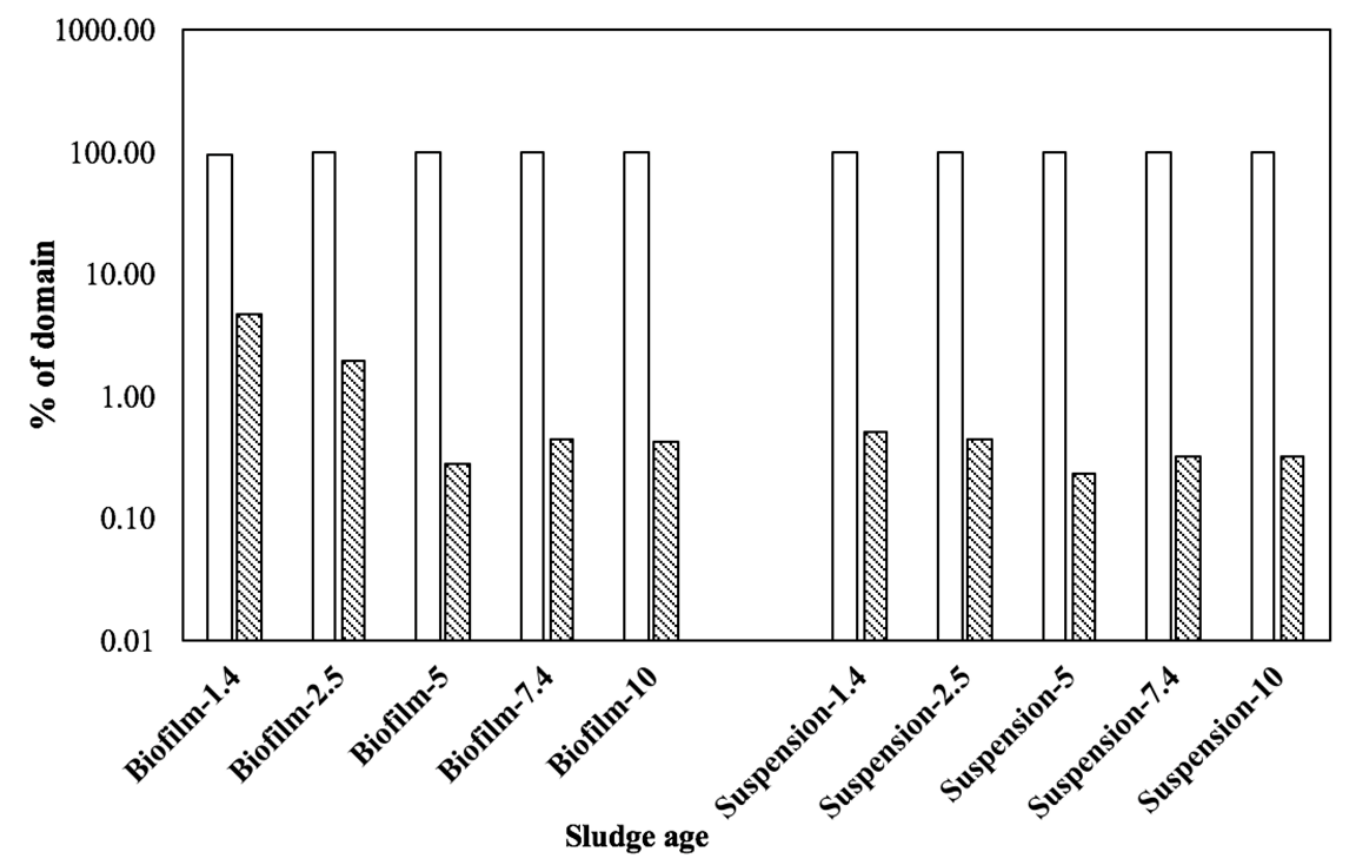

Figure 7. Evolution of the relative abundance of Archaea and Bacteria in the biofilm and suspension samples with sludge age. 
All genera of Bacteria and Archaea detected after amplicon sequencing of 16S rRNA gene were faced against the experimental performance described above (mainly against the production of electricity). On one hand, the archaeal community is dominated by genera involved in methanogenesis . Within the genera detected, the relevant ones are Methanosarcina, Methanocorpusculum, Methanopaera, Methanopyrus and Thermocladium, not taking part this last one in methanogenesis. Literature emphasizes the role of Methanosarcina in the methane production in the presence of acetate. Acetate can be converted into $\mathrm{CH}_{4}$ via methyl- $\mathrm{H}_{4} \mathrm{SPT}$ and via methyl-S-Com and $\mathrm{CO}_{2}$ is finally released from the carboxylic group (74) or throw the reduction of carbon dioxide, coming from the oxidation of acetate to methane avoiding or not the production of hydrogen as an intermediate step (75). In case of having a conductive support such as carbon cloth (or similar), the metabolism of Methanosarcina to produce methane can be enhanced in presence of acetate due to its decarboxylation, its capacity to grow slowly in an acetate medium and its ability to accept electron from the support (76). As well as Methanosarcina, Methanocorpusculum genus has been reported to be able to generate methane from $\mathrm{CO}_{2}$ and $\mathrm{H}_{2}$ (77). It can mean that Archaea community may have an indirect influence on the generation of electricity by carrying out processes than are useful for electrogenic microorganisms. It is important to point out that there is a large change in the diversity from the microorganisms observed in the mixed liquor and biofilm of the MFCs operated under and over 2.5 days. This change may be expected and it demonstrates that many phylotypes are washed out at low SRT from both, the mixed liquor and also from the biofilm. This observation also points out the strong connection between both cultures in each MFC.

On the other hand, the production of electricity should be mainly related to bacteria population. The energy recovery is mainly associated to Shewanella and Geobacter in literature (33). The presence of Geobacter is negligible, while the presence of Shewanella increases with the sludge age, opposite to the direction in which the production of electricity increases (it can be related 
to its slow growth). But despite of the presence of Shewanella and other known electrogenic genera such as Pseudomonas and Arcobacter $(36,42,78)$, there was only a small fraction of microorganisms whose abundance varies in a similar fashion and also follows the same trend than the generation of electricity. These small fractions are included in Figure 8, as they are the candidates to be more related to the production of electricity inside the population. As it can be seen the following genus of Bacteria fit well this trend: Desulfurumonas, Solitalea, Syntrophothermus, Acholeplasma, Propionicimonas, Sphaerochaeta and Desulfobacula.

Among the Bacteria selected, despite of being typically a marine microorganism that grows by oxidizing acetate under anaerobically conditions, Desulfuromonas acetoxidans are known to be susceptible to produce electrogenic activity and, thus, it has been proved to be able to carry out electron transfer to the electrode $(4,79)$. The genus Sphaerochaeta was detected in microbial electrolizer cells $(33,80)$. The action of Sphaerochaeta maybe consistent with the probable generation of $\mathrm{H}_{2}$ in the methanogenesis carried out by the Archaea domain. On the other hand, the genus of Propionicimonas is believed to take part in the mediated transfer through the production of phenazines or other soluble electron shuttles susceptible to be used in other metabolic pathways (49). Regarding the other microorganisms detected (Desulfurumonas, Solitalea, Syntrophothermus, Acholeplasma, Propionicimonas, Sphaerochaeta and Desulfobacula), no information that relates them to MFC has been found in literature.

It is important to highlight that the despite of being quite similar the abundance of Bacteria and Archaea either in biofilm and suspension, it is higher in the biofilm. It means that suspended microorganisms increase the efficiency of the current generation while the electricity production is mainly governed by the biofilm, what makes this device more robust (20). This fact can be linked to the washes that the suspension microorganisms experience in the bulk. 

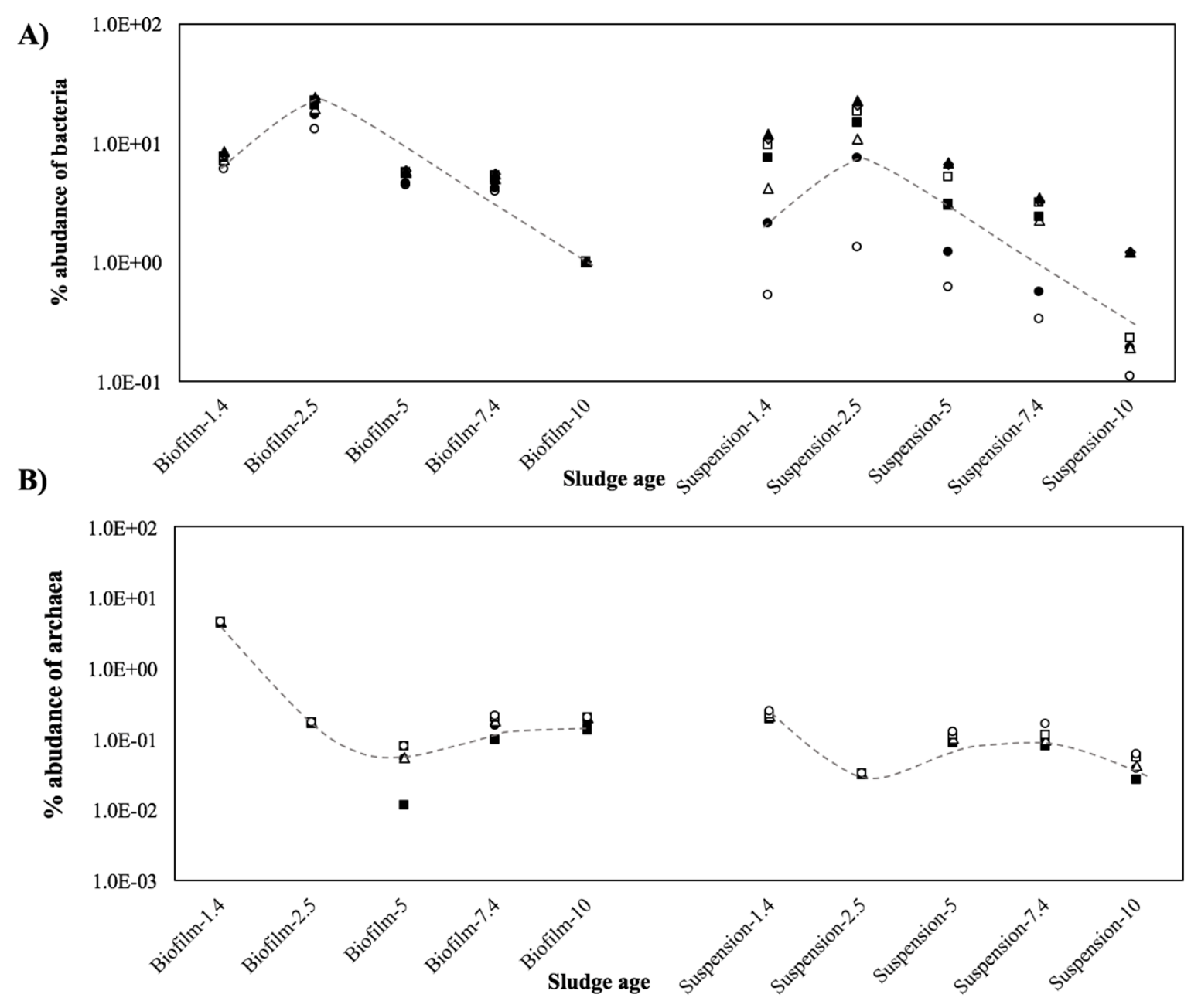

Figure 8. A) Evolution of the genera relative abundances of Bacteria in biofilm and suspension

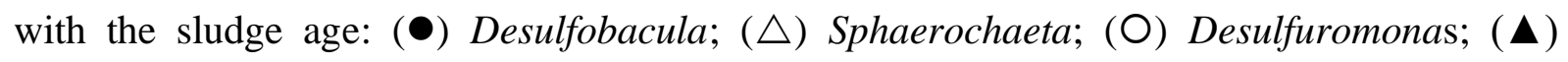
Solitalea; $(\diamond)$ Syntrophothermus; $(\square)$ Acholeplasma; (•) Propionicimonas. B) Evolution of the genera relative of Archaea in biofilm and suspension with the sludge age: (O) Methanocorpusculum; ( $\triangle$ ) Methanosphaera; (•) Methanosarcina; ( $\square)$ Thermocladium; Methanopyrus.

Hence, in comparing the macroscopic effects of the generation of electric current with the microbial detected populations, it is important to point out that the changes observed in the relative abundances of the two classical electrogenic microorganisms Shewanella and Geobacter do not match with the changes in the current produced and opposite, other 
microorganisms, either Bacteria and Archaea composition may help to explain this behavior. This is an important point because the further development of MFC technology should not be based on pure cultures but on the most effective and robust mixed cultures and consortias like the ones formed in this study are representative of a successful bio-electrogenic culture.

\section{Conclusions}

- High performances are achieved working with mini-scale air-breathing MFCs with small electrode surface areas.

- The bio-electrogenic activity depends on the sludge age and within the evaluated range, the operation at 2.5 days results in a huge coulombic efficiency of about $50 \%$, which yield $35 \mathrm{~A} \mathrm{~m}^{-2}$ of maximum current density.

- Desulfuromonas, Syntrophothermus, Solitalea, Acholeplasma, Propionicimonas, Desulfobacula and Sphaerochaeta can be proposed as potential responsible for the bioelectrogenic activity because their concentration changes in the same fashion than the bio-electrochemical activity. The presence of this species was more abundant in biofilm than in suspension.

\section{Acknowledgements}

Financial support from the AEI (Agencia Estatal de Investigación) of the Spanish Ministry of Economy and Competitiveness (MINECO) through project CTQ2013-49748-EXP (Explora Program) is gratefully acknowledged 


\section{References}

1. Penteado ED, Fernandez-Marchante CM, Zaiat M, Cañizares P, Gonzalez ER, Rodrigo MA. Influence of sludge age on the performance of MFC treating winery wastewater. Chemosphere. 2016;151:163-70.

2. D'Angelo A, Mateo S, Scialdone $O$, Cañizares $P$, Fernandez-Morales FJ, Rodrigo MA. Optimization of the performance of an air-cathode MFC by changing solid retention time. Journal of Chemical Technology and Biotechnology. 2017.

3. Ledezma P, Greenman J, leropoulos I. MFC-cascade stacks maximise COD reduction and avoid voltage reversal under adverse conditions. Bioresource Technology. 2013;134:158-65.

4. Sun G, Thygesen A, Meyer AS. Acetate is a superior substrate for microbial fuel cell initiation preceding bioethanol effluent utilization. Applied Microbiology and Biotechnology. 2015;99(11):490515.

5. Mateo S, Gonzalez del Campo A, Lobato J, Rodrigo M, Cañizares P, Fernandez-Morales FJ. Longterm effects of the transient COD concentration on the performance of microbial fuel cells. Biotechnology progress. 2016;32(4):883-90.

6. Sawant SY, Han TH, Cho MH. Metal-free carbon-based materials: Promising electrocatalysts for oxygen reduction reaction in microbial fuel cells. International Journal of Molecular Sciences. 2017;18(1).

7. Lobato J, Zamora H, Plaza J, Cañizares P, Rodrigo MA. Enhancement of high temperature PEMFC stability using catalysts based on Pt supported on SiC based materials. Applied Catalysis B: Environmental. 2016;198:516-24.

8. Lefebvre O, Ooi WK, Tang Z, Abdullah-Al-Mamun M, Chua DHC, Ng HY. Optimization of a Ptfree cathode suitable for practical applications of microbial fuel cells. Bioresource Technology. 2009;100(20):4907-10.

9. Lefebvre O, Al-Mamun A, Ooi WK, Tang Z, Chua DHC, Ng HY. An insight into cathode options for microbial fuel cells. Water Science and Technology2008. p. 2031-7.

10. Chang YY, Zhao HZ, Zhong C, Xue A. Effects of different Pt-M (M = Fe, Co, Ni) alloy as cathodic catalyst on the performance of two-chambered microbial fuel cells. Russian Journal of Electrochemistry. 2014;50(9):885-90.

11. Lobato J, Cañizares P, Fernández FJ, Rodrigo MA. An evaluation of aerobic and anaerobic sludges as start-up material for microbial fuel cell systems. New biotechnology. 2012;29(3):415-20.

12. del Campo AG, Cañizares P, Lobato J, Rodrigo M, Morales FJF. Effects of External Resistance on Microbial Fuel Cell's Performance. Environment, Energy and Climate Change II: Springer; 2014. p. 17597.

13. del Campo AG, Lobato J, Cañizares P, Rodrigo MA, Morales FJF. Short-term effects of temperature and COD in a microbial fuel cell. Applied Energy. 2013;101:213-7.

14. Chouler J, Padgett GA, Cameron PJ, Preuss K, Titirici MM, leropoulos I, et al. Towards effective small scale microbial fuel cells for energy generation from urine. Electrochimica Acta. 2016;192:89-98.

15. Qian F, Morse DE. Miniaturizing microbial fuel cells. Trends in Biotechnology. 2011;29(2):62-9.

16. Choi S. Microscale microbial fuel cells: Advances and challenges. Biosensors and Bioelectronics. 2015;69:8-25.

17. Zhao N, Angelidaki I, Zhang Y. Electricity generation and microbial community in response to short-term changes in stack connection of self-stacked submersible microbial fuel cell powered by glycerol. Water Research. 2017;109:367-74.

18. leropoulos IA, Greenman J, Melhuish C. Miniature microbial fuel cells and stacks for urine utilisation. International Journal of Hydrogen Energy. 2013;38(1):492-6.

19. Ieropoulos I, Greenman J, Melhuish C. Microbial fuel cells based on carbon veil electrodes: Stack configuration and scalability. International Journal of Energy Research. 2008;32(13):1228-40.

20. Venkata Mohan S, Veer Raghavulu S, Sarma PN. Influence of anodic biofilm growth on bioelectricity production in single chambered mediatorless microbial fuel cell using mixed anaerobic consortia. Biosensors and Bioelectronics. 2008;24(1):41-7. 
21. Dumas C, Basseguy R, Bergel A. DSA to grow electrochemically active biofilms of Geobacter sulfurreducens. Electrochimica Acta. 2008;53(7):3200-9.

22. Schröder U. Anodic electron transfer mechanisms in microbial fuel cells and their energy efficiency. Physical Chemistry Chemical Physics. 2007;9(21):2619-29.

23. Reguera G, Nevin KP, Nicoll JS, Covalla SF, Woodard TL, Lovley DR. Biofilm and nanowire production leads to increased current in Geobacter sulfurreducens fuel cells. Applied and Environmental Microbiology. 2006;72(11):7345-8.

24. Liu H, Cheng S, Logan BE. Production of electricity from acetate or butyrate using a singlechamber microbial fuel cell. Environmental Science and Technology. 2005;39(2):658-62.

25. Rabaey K, Boon N, Siciliano SD, Verhaege M, Verstraete W. Biofuel cells select for microbial consortia that self-mediate electron transfer. Applied and Environmental Microbiology. 2004;70(9):5373-82.

26. Karra U, Huang G, Umaz R, Tenaglier C, Wang L, Li B. Stability characterization and modeling of robust distributed benthic microbial fuel cell (DBMFC) system. Bioresource technology. 2013;144:47784.

27. Kim JR, Beecroft NJ, Varcoe JR, Dinsdale RM, Guwy AJ, Slade RCT, et al. Spatiotemporal development of the bacterial community in a tubular longitudinal microbial fuel cell. Applied microbiology and biotechnology. 2011;90(3):1179-91.

28. Cercado B, Byrne N, Bertrand M, Pocaznoi D, Rimboud M, Achouak W, et al. - Garden compost inoculum leads to microbial bioanodes with potential-independent characteristics.- 276.

29. Miceli lii JF, Parameswaran P, Kang D-W, Krajmalnik-Brown R, Torres CsI. Enrichment and analysis of anode-respiring bacteria from diverse anaerobic inocula. Environmental science \&amp; technology. 2012;46(18):10349-55.

30. Schamphelaire LD, Bossche LVD, Dang HS, Höfte M, Boon N, Rabaey K, et al. Microbial fuel cells generating electricity from rhizodeposits of rice plants. Environmental Science \&amp; Technology. 2008;42(8):3053-8.

31. Rousseau R, Santaella C, Achouak W, Godon JJ, Bonnafous A, Bergel A, et al. Correlation of the Electrochemical Kinetics of High-Salinity-Tolerant Bioanodes with the Structure and Microbial Composition of the Biofilm. ChemElectroChem. 2014;1(11):1966-75.

32. Sulonen MLK, Kokko ME, Lakaniemi A-M, Puhakka JA. Electricity generation from tetrathionate in microbial fuel cells by acidophiles. Journal of hazardous materials. 2015;284:182-9.

33. Mäkinen AE, Lay C-H, Nissilä ME, Puhakka JA. Bioelectricity production on xylose with a compost enrichment culture. international journal of hydrogen energy. 2013;38(35):15606-12.

34. Sun G, Rodrigues DDS, Thygesen A, Daniel G, Fernando D, Meyer AS. Inocula selection in microbial fuel cells based on anodic biofilm abundance of Geobacter sulfurreducens. Chinese Journal of Chemical Engineering. 2016;24(3):379-87.

35. Richter H, McCarthy K, Nevin KP, Johnson JP, Rotello VM, Lovley DR. Electricity generation by Geobacter sulfurreducens attached to gold electrodes. Langmuir. 2008;24(8):4376-9.

36. Zhang $\mathrm{W}, \mathrm{Wu} \mathrm{H}$, Hsing IM. Real-Time Label-Free Monitoring of Shewanella oneidensis MR-1 Biofilm Formation on Electrode During Bacterial Electrogenesis Using Scanning Electrochemical Microscopy. Electroanalysis. 2015;27(3):648-55.

37. Sacco NJ, Figuerola ELM, Pataccini G, Bonetto MC, Erijman L, Cortón E. Performance of planar and cylindrical carbon electrodes at sedimentary microbial fuel cells. Bioresource Technology. 2012;126:328-35.

38. Martins G, Peixoto L, Ribeiro DC, Parpot P, Brito AG, Nogueira R. Towards implementation of a benthic microbial fuel cell in lake Furnas (Azores): Phylogenetic affiliation and electrochemical activity of sediment bacteria. Bioelectrochemistry. 2010;78(1):67-71.

39. Ketep SF, Bergel A, Bertrand M, Barakat M, Achouak W, Fourest E. Forming microbial anodes with acetate addition decreases their capability to treat raw paper mill effluent. Bioresource Technology. 2014;164:285-91. 
40. Zhang T, Bain TS, Barlett MA, Dar SA, Snoeyenbos-West OL, Nevin KP, et al. Sulfur oxidation to sulfate coupled with electron transfer to electrodes by Desulfuromonas strain TZ1. Microbiology. 2014;160(1):123-9.

41. Badalamenti JP, Summers ZM, Chan CH, Gralnick JA, Bond DR. Isolation and Genomic Characterization of 'Desulfuromonas soudanensis WTL', a Metal-and Electrode-Respiring Bacterium from Anoxic Deep Subsurface Brine. Frontiers in Microbiology. 2016;7.

42. Varanasi JL, Sinha P, Das D. Maximizing power generation from dark fermentation effluents in microbial fuel cell by selective enrichment of exoelectrogens and optimization of anodic operational parameters. Biotechnology Letters. 2017:1-10.

43. Hodgson DM, Smith A, Dahale S, Stratford JP, Li JV, Grüning A, et al. Segregation of the anodic microbial communities in a microbial fuel cell cascade. Frontiers in Microbiology. 2016;7(MAY).

44. He GQ, Kong $Q$, Chen $Q H$, Ruan $H$. Batch and fed-batch production of butyric acid by Clostridium butyricum ZJUCB. Journal of Zhejiang University: Science. 2005;6 B(11):1076-80.

45. Li J, Yuan L, Liu Z, Zhou G. Effect of microbial fermentation on electricity production of microbial fuel cells. Chinese Journal of Environmental Engineering. 2016;10(8):4049-54.

46. Lee Y-Y, Kim TG, Cho K-S. Characterization of the COD removal, electricity generation, and bacterial communities in microbial fuel cells treating molasses wastewater. Journal of Environmental Science and Health, Part A. 2016;51(13):1131-8.

47. Park HS, Kim BH, Kim HS, Kim HJ, Kim GT, Kim M, et al. A novel electrochemically active and Fe (III)-reducing bacterium phylogenetically related to Clostridium butyricum isolated from a microbial fuel cell. Anaerobe. 2001;7(6):297-306.

48. Ho IP, Sanchez D, Sung KC, Yun M. Racterial communities on electron-ream Pt-deposited electrodes in a mediator-less microbial fuel cell. Environmental Science and Technology. 2008;42(16):6243-9.

49. Michaelidou U, Ter Heijne A, Euverink GJW, Hamelers HVM, Stams AJM, Geelhoed JS. Microbial communities and electrochemical performance of titanium-based anodic electrodes in a microbial Fuel Cell. Applied and Environmental Microbiology. 2011;77(3):1069-75.

50. Rodrigo M, Seco A, PenyaRoja J, Ferrer J. Influence of sludge age on enhanced phosphorus removal in biological systems. Water Science and Technology. 1996;34(1-2):41-8.

51. Park D, Zeikus J. Impact of electrode composition on electricity generation in a singlecompartment fuel cell using Shewanella putrefaciens. Applied Microbiology and Biotechnology. 2002;59(1):58-61.

52. Rodríguez Mayor L, Villaseñor Camacho J, Fernández Morales FJ. Operational optimisation of pilot scale biological nutrient removal at the Ciudad Real (Spain) domestic wastewater treatment plant. Water, Air, and Soil Pollution. 2004;152(1-4):279-96.

53. Zhang $\mathrm{Y}, \mathrm{Ng} \mathrm{CK}$, Cohen $\mathrm{Y}, \mathrm{Cao} \mathrm{B}$. Cell growth and protein expression of Shewanella oneidensis in biofilms and hydrogel-entrapped cultures. Molecular BioSystems. 2014;10(5):1035-42.

54. Holmes DE, Giloteaux L, Barlett M, Chavan MA, Smith JA, Williams KH, et al. Molecular analysis of the In situ growth rates of subsurface geobacter species. Applied and Environmental Microbiology. 2013;79(5):1646-53.

55. Mateo S, D'Angelo A, Scialdone O, Canizares P, Andres Rodrigo M, Jesus Fernandez-Morales F. The influence of sludge retention time on mixed culture microbial fuel cell start-ups. Biochemical Engineering Journal. 2017;123:38-44.

56. D'Angelo A, Mateo S, Scialdone O, Canizares P, Jesus Fernandez-Morales F, Andres Rodrigo M. Optimization of the performance of an air-cathode MFC by changing solid retention time. Journal of Chemical Technology and Biotechnology. 2017;92(7):1746-55.

57. Penteado ED, Maria Fernandez-Marchante C, Zaiat M, Canizares P, Gonzalez ER, Andres Rodrigo M. Influence of sludge age on the performance of MFC treating winery wastewater. Chemosphere. 2016;151:163-70.

58. Asensio Y, Montes IB, Fernandez-Marchante CM, Lobato J, Canizares P, Rodrigo MA. Selection of cheap electrodes for two-compartment microbial fuel cells. Journal of Electroanalytical Chemistry. 2017;785:235-40. 
59. Mateo $S$, Rodrigo M, Fonseca LP, Cañizares P, Fernandez-Morales FJ. Oxygen availability effect on the performance of air-breathing cathode microbial fuel cell. Biotechnology Progress. 2015;31(4):900-7.

60. Logan BE, Hamelers B, Rozendal R, Schröder U, Keller J, Freguia S, et al. Microbial fuel cells: methodology and technology. Environmental science \&amp; technology. 2006;40(17):5181-92.

61. Water Environment F, Water Pollution Control F, American Water Works A, American Public Health A. Standard methods for the examination of water and wastewater. 1905:v.

62. Schmieder R, Edwards R. Quality control and preprocessing of metagenomic datasets. Bioinformatics. 2011;27(6):863-4.

63. Aronesty E. ea-utils: Command-line tools for processing biological sequencing data. Expression Analysis, Durham, NC. 2011.

64. Edgar RC, Haas BJ, Clemente JC, Quince C, Knight R. UCHIME improves sensitivity and speed of chimera detection. Bioinformatics. 2011;27(16):2194-200.

65. Cole JR, Wang Q, Cardenas E, Fish J, Chai B, Farris RJ, et al. The Ribosomal Database Project: improved alignments and new tools for rRNA analysis. Nucleic acids research. 2008;37(suppl_1):D141D5.

66. Asensio Y, Montes IB, Fernandez-Marchante CM, Lobato J, Cañizares P, Rodrigo MA. Selection of cheap electrodes for two-compartment microbial fuel cells. Journal of Electroanalytical Chemistry. 2017;785:235-40.

67. Schilirò T, Tommasi T, Armato C, Hidalgo D, Traversi D, Bocchini S, et al. The study of electrochemically active planktonic microbes in microbial fuel cells in relation to different carbonbased anode materials. Energy. 2016;106:277-84.

68. Hidalgo D, Tommasi T, Velayutham K, Ruggeri B. Long term testing of Microbial Fuel Cells: Comparison of different anode materials. Bioresource Technology. 2016;219:37-44.

69. Fan Y, Hu H, Liu H. Enhanced Coulombic efficiency and power density of air-cathode microbial fuel cells with an improved cell configuration. Journal of Power Sources. 2007;171(2):348-54.

70. Ringeisen BR, Henderson E, Wu PK, Pietron J, Ray R, Little B, et al. High power density from a miniature microbial fuel cell using Shewanella oneidensis DSP10. Environmental science \&amp; technology. 2006;40(8):2629-34.

71. Han Y, Yu C, Liu H. A microbial fuel cell as power supply for implantable medical devices. Biosensors and Bioelectronics. 2010;25(9):2156-60.

72. Hidalgo D, Tommasi T, Bocchini S, Chiolerio A, Chiodoni A, Mazzarino I, et al. Surface modification of commercial carbon felt used as anode for Microbial Fuel Cells. Energy. 2016;99:193201.

73. Fan Y, Sharbrough E, Liu H. Quantification of the internal resistance distribution of microbial fuel cells. Environmental Science and Technology. 2008;42(21):8101-7.

74. Beckmann S, Welte C, Li X, Oo YM, Kroeninger L, Heo Y, et al. Novel phenazine crystals enable direct electron transfer to methanogens in anaerobic digestion by redox potential modulation. Energy and Environmental Science. 2016;9(2):644-55.

75. Yin $Q$, Zhu X, Zhan G, Bo T, Yang $Y$, Tao $Y$, et al. Enhanced methane production in an anaerobic digestion and microbial electrolysis cell coupled system with co-cultivation of Geobacter and Methanosarcina. Journal of Environmental Sciences (China). 2016;42:210-4.

76. Dang Y, Holmes DE, Zhao Z, Woodard TL, Zhang Y, Sun D, et al. Enhancing anaerobic digestion of complex organic waste with carbon-based conductive materials. Bioresource Technology. 2016;220:516-22.

77. Sun R, Zhou A, Jia J, Liang Q, Liu Q, Xing D, et al. Characterization of methane production and microbial community shifts during waste activated sludge degradation in microbial electrolysis cells. Bioresource Technology. 2015;175:68-74.

78. Wu D, Xing D, Mei X, Liu B, Guo C, Ren N. Electricity generation by Shewanella sp. HN-41 in microbial fuel cells. International Journal of Hydrogen Energy. 2013;38(35):15568-73.

79. Bond DR, Holmes DE, Tender LM, Lovley DR. Electrode-reducing microorganisms that harvest energy from marine sediments. Science. 2002;295(5554):483-5. 
80. Park T-J, Ding W, Cheng S, Brar MS, Ma APY, Tun HM, et al. Microbial community in microbial fuel cell (MFC) medium and effluent enriched with purple photosynthetic bacterium (Rhodopseudomonas sp.). AMB Express. 2014;4:22-. 